Original Paper

\title{
Development and Evaluation of Event-Specific Quantitative PCR Method for Genetically Modified Soybean A2704-12
}

(Received July 23, 2010)

\author{
Reona Takabatake ${ }^{1}$, Hiroshi Akiyama ${ }^{2}$, Kozue Sakata ${ }^{2}$, Mari Onishi ${ }^{3}$, Tomohiro Koiwa ${ }^{4}$, \\ Satoshi Futo ${ }^{3}$, Yasutaka Minegishi ${ }^{5}$, Reiko Teshima ${ }^{2}$, Junichi MANO ${ }^{1}$, \\ Satoshi Furui ${ }^{1}$ and Kazumi KitTA ${ }^{1, *}$ \\ ${ }^{1}$ Analytical Science Division, National Food Research Institute, National Agriculture and \\ Food Research Organization: 2-1-12 Kannondai, Tsukuba, Ibaraki 305-8642, Japan; \\ ${ }^{2}$ National Institute of Health Sciences: 1-18-1 Kamiyoga, Setagaya-ku, Tokyo 158-8501, Japan; \\ ${ }^{3}$ FASMAC Co., Ltd.: 5-1-3 Midorigaoka, Atsugi, Kanagawa 243-0041, Japan; \\ ${ }^{4}$ Food and Agricultural Materials Inspection Center: 2-1 Shintoshin, \\ Chuo-ku, Saitama, Saitama 330-9731, Japan; \\ ${ }^{5}$ NIPPON GENE Co., Ltd.: 1-8-7 Toiyamachi, Toyama, Toyama 930-0834, Japan; \\ * Corresponding author
}

\begin{abstract}
A novel real-time PCR-based analytical method was developed for the event-specific quantification of a genetically modified (GM) soybean event; A2704-12. During the plant transformation, DNA fragments derived from pUC19 plasmid were integrated in A2704-12, and the region was found to be A2704-12 specific. The pUC19-derived DNA sequences were used as primers for the specific detection of A2704-12. We first tried to construct a standard plasmid for A2704-12 quantification using pUC19. However, non-specific signals appeared with both qualitative and quantitative PCR analyses using the specific primers with pUC19 as a template, and we then constructed a plasmid using pBR322. The conversion factor $\left(C_{\mathrm{f}}\right)$, which is required to calculate the amount of the genetically modified organism (GMO), was experimentally determined with two real-time PCR instruments, the Applied Biosystems 7900HT and the Applied Biosystems 7500. The determined $C_{\mathrm{f}}$ values were both 0.98 . The quantitative method was evaluated by means of blind tests in multi-laboratory trials using the two real-time PCR instruments. The limit of quantitation for the method was estimated to be $0.1 \%$. The trueness and precision were evaluated as the bias and reproducibility of relative standard deviation $\left(\mathrm{RSD}_{\mathrm{R}}\right)$, and the determined bias and $\mathrm{RSD}_{\mathrm{R}}$ values for the method were each less than $20 \%$. These results suggest that the developed method would be suitable for practical analyses for the detection and quantification of A2704-12.
\end{abstract}

Key words: A2704-12; event-specific; genetically modified (GM); real-time PCR; soybean

\section{Introduction}

The use of genetically modified (GM) crops has been increasing since their commercialization in 1996. After more than a decade, the global area of GM crops has increased approximately 80 -fold, from 1.7 million hectares in six countries in 1996, to 134 million hectares in 25 countries in $2009^{1)}$. The utilization of GM crops has generated substantial economical benefits, but, nevertheless, has been subjected to rigid control. The presence of GM products in crops or foods is obliged to be labeled in the European Union (EU), Korea, Japan, Australia, and many other countries. In Japan, the genetically modified organism (GMO) labeling system has been defined by the "JAS law"*1 and the "Food Sanitation law"*2, and the thresholds for the uninten-

*1 Notification No. 1173 (Oct. 1, 2007); Ministry of Agriculture, Forestry and Fisheries of Japan (2007) tional commingling level for approved GM soy and maize were both set at $5 \%{ }^{2), * 3, * 4}$.

The Japanese food self-sufficiency ratio on a calorie supply basis has been hovering around 40\% in recent years, but the ratios among grains, except for rice, are extremely low*5. Among them, soybeans are one of the most important crops in Japan. The domestic consump-

\footnotetext{
*2 Notification No. 79 (Mar. 15, 2001); Ministry of Heath, Labour and Welfare of Japan (2001)

*3 Notification No. 110 (Mar. 27, 2001); Department of Food Safety, Ministry of Health, Labour and Welfare of Japan (2001)

*4 Notification No. 517 (Mar. 31, 2000); Ministry of Agriculture, Forestry and Fisheries of Japan (2000)

*5 Annual Report on Food, Agriculture and Rural Areas in Japan FY2006 Policies on Food, Agriculture and Rural Areas in Japan FY2007, Summary of Ministry of Agriculture, Forestry and Fisheries of Japan; http://www.maff.go. jp/e/pdf/fy2006_rep.pdf
} 
tion of soybeans as oil and food is over 4 million tons/ year, but the self-sufficiency ratio for this crop is only approximately $5 \% * 6$, i.e., more than $90 \%$ of soybeans are imported into Japan. Most of them are imported from the United States, where GM soybeans account for more than $90 \%$ of the soybean cultivation areas ${ }^{1)}$. There are several approved GM soybean events in Japan*7. The first commercial GM soybean was a glyphosate-tolerant soybean (GTS), event 40-3-2 [Roundup Ready ${ }^{\circledR}$ soybean (RRS)]. RRS has received regulatory approval in many countries, including Japan. Next, glufosinate-tolerant soybeans such as A2704-12 and A5547-127 were approved, and then the second generation of GTS, MON89788, was recently approved.

A2704-12 and A5547-127 contain the same transgene cassette consisting of cauliflower mosaic virus 35 S promoter (P35S), the synthetic pat gene which codes phosphinothricin $N$-acetyltransferase derived from Streptomyces viridochromogenes ${ }^{3), 4)}$, and cauliflower mosaic virus 35S terminator (T35S $)^{5), 6)}$. Many methods for analyzing RRS and MON89788 have been published ${ }^{7)-11)}$, but there is no report on quantification of A2704-12, although A2704-12 is now being commercially cultivated.

In this study, we developed a new quantitative method for A2704-12, using event-specific PCR, and then evaluated the method with two multi-laboratory trials. The development of the quantitative method was mainly carried out in the National Food Research Institute, and the interlaboratory collaborative study was independently conducted with the National Institute of Health Sciences (NIHS).

\section{Materials and Methods}

\section{Plant materials}

Regarding soybean and maize seeds, A2704-12 and a non-GM isoline of A2704-12 used as a non-GM soy sample were kindly provided by the developer, MON 89788, RRS, MON810, MON863, MON88017, and NK 603 by Monsanto Company (St. Louis, MO, USA), Bt11, Event176, GA21, and MIR604 by Syngenta Seeds AG (Basel, Switzerland), TC1507 and DAS59122 by Pioneer Hi-Bred International (Johnston, IA, USA), and T25 was directly imported from the USA. QC9651 maize from Quality Technology International, Inc. (Elgin, IL, USA) was used as a non-GM maize. Seeds of rice (Oryza sativa) variety Kinuhikari, wheat (Triticum aestivum) variety Haruyutaka, and barley (Hordeum vulgare) variety Harrington were harvested in Japan. A5547-127 was

\footnotetext{
*6 Ministry of Agriculture, Forestry and Fisheries of Japan; http://www.maff.go.jp/j/seisan / ryutu/daizu/d_data/ pdf/011_juyou.pdf

*7 List of products that have undergone safety assessment and been announced in the Official Gazette (May 12, 2010) of the Department of Food Safety, Ministry of Health, Labour, and Welfare; http://www.mhlw.go.jp/english/ topics/food/pdf/sec01-2.pdf
}

purchased from the American Oil Chemists' Society (AOCS) (Urbana, IL, USA) as DNA extract (AOCS 0707C; above $999.9 \mathrm{ng} / \mu \mathrm{L}$ of GM DNA).

\section{Oligonucleotide primers and probes}

For the specific detection of A2704-12, a pair of primers (KVM175; 5'-GCAAAAAAGCGGTTAGCTCCT$3^{\prime}$ and SMO001; 5'-ATTCAGGCTGCGCAACTGTT-3') and a fluorescent dye-labeled probe (TM031; 5'-CGGTCCTCCGATCGCCCTTCC-3') were used for real-time PCR. The sequences of these primers and probe were taken from the report of the European Commission's Joint Research Centre (JRC, IRMM, Retieseweg, Geel, Belgium)*8. Le $1^{12)}$ was used as a soybean-specific endogenous reference DNA for quantitative analysis. For specific detection of Le1, the primers (Le1n02-5'; 5'GCCCTCTACTCCACCCCCA-3' and Le1n02-3'; $5^{\prime}$ GCCCATCTGCAAGCCTTTTT-3') and fluorescent dyelabeled probe (Le1-Taq; 5'-AGCTTCGCCGCTTCCTTCAACTTCAC-3') were used ${ }^{8)}$. The oligonucleotide primers and TaqMan ${ }^{\circledR}$ probes were synthesized by FASMAC Co., Ltd. (Kanagawa, Japan) and Life Technologies (Carlsbad, CA, USA), respectively. The oligonucleotide probes were labeled with 6-carboxyfluorescein (FAM) at the $5^{\prime}$ ends and 6-carboxytetramethylrhodamine (TAMRA) at the $3^{\prime}$ ends.

\section{Preparation of calibrant plasmid}

Specific sequence fragments from A2704-12 and the endogenous soybean Le1 gene were synthesized as a single oligonucleotide in tandem and inserted into a pBR322 vector. The constructed plasmid was purified by equilibrium centrifugation in a $\mathrm{CsCl}$ gradient to collect the covalently closed circular DNA, which was linearized by cutting at a restriction site located outside the integrated fragment. The concentration of the linearized DNA was calculated from the ultraviolet (UV) absorbance measured with a spectrophotometer, DU 800 (Beckman Coulter, Fullerton, CA, USA) as described previously ${ }^{8}$, and converted to the molar concentration. The solution was then diluted to theoretical concentrations of 20,125, 1,500,20,000, and 250,000 copies per $2.5 \mu \mathrm{L}$, with $5 \mathrm{ng} / \mu \mathrm{L}$ of ColE1 DNA (NIPPON GENE, Tokyo, Japan) solution. Finally, the copy numbers of the diluted plasmids were adjusted based on the Le1 segment of pMulSL2, which has been adopted in the Japanese standard analytical method ${ }^{* 9}$, using quantitative real-time PCR analyses.

\footnotetext{
*8 Event-specific method for the quantification of soybean line A2704-12 using real-time PCR; http://gmo-crl.jrc.ec. europa. eu / summaries / A 2704-12_soybean_validated _ Method.pdf

*9 Japanese Agricultural Standard (JAS) analytical test handbook: genetically modified food quality, labeling analysis manual for individual products (2002). The Food and Agricultural Materials Inspection Center, Japan; http://www. famic.go.jp/technical_information / jashandbook / index. html
} 


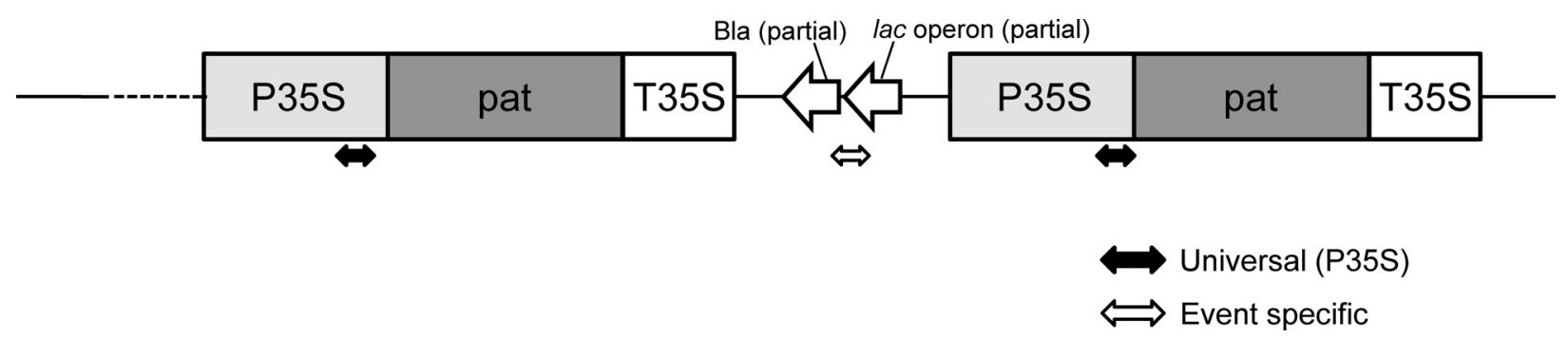

Fig. 1. Schematic diagrams of the target positions in A2704-12

The event-specific target sequence of A2704-12 is the junction region of two partial sequences derived from the bla gene and lac operon, corresponding to positions 248-267 and 2036-2056 in pUC19, between the two pat gene cassettes. The nucleotide sequence of pUC19 is available under accession number L09137.

\section{Preparation of test samples and DNA extraction}

To evaluate the quantitative method, we used six mixing levels of test materials containing $0 \%, 0.10 \%$, 0.50\%, 1.0\%, 5.0\%, and 10.0\% A2704-12. To prepare the mixed samples, we ground A2704-12 seeds and non-GM seeds using MM200 and ZM100 grinders (Retsch, Haan, Germany), respectively, as described previously ${ }^{13)}$, and then mixed the samples on a weightto-weight basis. DNA was extracted from the ground materials using GM quicker (NIPPON GENE) according to the manufacturer's manual. The concentration and quality of extracted DNA solutions were evaluated by measuring UV absorbance with a spectrophotometer, ND-100 (NanoDrop Technologies, Wilmington, DE, USA). Soybean genomic DNA solutions were adjusted to a concentration of $20 \mathrm{ng} / \mu \mathrm{L}$.

\section{Qualitative PCR}

Qualitative PCR using a thermal cycler, GeneAmp PCR system 9700 (Life Technologies), and agarose gel electrophoresis were performed as described previously by Kuribara et al. (2002).

\section{Quantitative PCR}

TaqMan ${ }^{\circledR}$ real-time PCR assays were carried out using the Applied Biosystems 7900HT (AB 7900) or the Applied Biosystems 7500 (AB 7500) (Life Technologies), in $25 \mu \mathrm{L}$ final volume, containing $50 \mathrm{ng}$ of sample DNA, $12.5 \mu \mathrm{L}$ Universal Master Mix (Life Technologies), $0.5 \mu$ $\mathrm{M}$ primer pairs, and $0.2 \mu \mathrm{M}$ probe. The step-cycle program was as follows: $2 \mathrm{~min}$ at $50^{\circ} \mathrm{C}, 10 \mathrm{~min}$ at $95^{\circ} \mathrm{C}, 45$ cycles, $30 \mathrm{~s}$ at $95^{\circ} \mathrm{C}$, and $1 \mathrm{~min}$ at $59^{\circ} \mathrm{C}$. In the reaction plate, each sample was measured in triplicate.

\section{Multi-laboratory trial}

Multi-laboratory trials were performed with the AB 7900 and the AB 7500 independently and consisted of 2 separate stages: measurement of the $C_{\mathrm{f}}$ value and a blind test. All measurements were conducted by 5 laboratories for the AB 7900 and 3 laboratories for the AB 7500. Experimental protocols were provided by the NIHS. Quantitative real-time PCR was performed with primers, probes, Universal Master Mix, and blind DNA solutions supplied by NIHS.

The first stage was the experimental determination of the $C_{\mathrm{f}}$ value as the ratio of the copy number of recombinant DNA (r-DNA) to the taxon-specific sequence in the GM plant genome. To calculate the $C_{\mathrm{f}}$ value for A2704-12, we extracted the genomic DNA from genuine GM seeds and determined the copy numbers of r-DNA and taxon-specific sequences. The measurement was conducted twice at each laboratory. The $C_{\mathrm{f}}$ value for each real-time PCR instrument was separately determined as the mean of the obtained values.

A blind test was carried out as the second stage. Blind samples designed as blind duplicates of the soybean genomic DNAs extracted from 6 different concentrations of A2704-12, 0\%, 0.10\%, 0.50\%, 1.0\%, 5.0\% and $10.0 \%$, were sent to the participants. All participants were requested to submit the data from the realtime PCR analyses. All submitted data were analyzed by means of Cochran's test ${ }^{14)}$ and Grubbs' test ${ }^{15), 16)}$.

\section{Results and Discussion}

\section{Specificity of the PCR system for A2704-12}

A2704-12 contains two copies of the pat gene cassette inserted in a head-to-tail configuration*10. The biotic transformation of soybeans was conducted by microparticle bombardment with a pUC19-based plasmid containing the pat gene cassette. The pUC19 plasmid contains an antibiotic resistance gene; beta-lactamase (bla), and a lac operon, and several fragments derived from pUC19 DNA exist in the A2704-12 genome. Partial sequences derived from the bla gene and lac operon are integrated side-by-side between the two pat gene cassettes $^{* 10}$, and this site is unique to A2704-12. For specific detection of A2704-12, the junction site was used (Fig. 1). The specificity of the primer set was confirmed by qualitative PCR. The expected 64-bp product was detected using genomic DNA solutions from A2704-12, but not from non-GM soybeans; GM soybeans RRS, MON89788, and another glufosinatetolerant soybean: A5547-127; non-GM maize; 11 lines of GM maize; rice, wheat, and barley; and the no template control (Fig. 2).

\footnotetext{
*10 Agbios database. http://www.cera-gmc.org/?action $=$ gm crop_database\&
} 


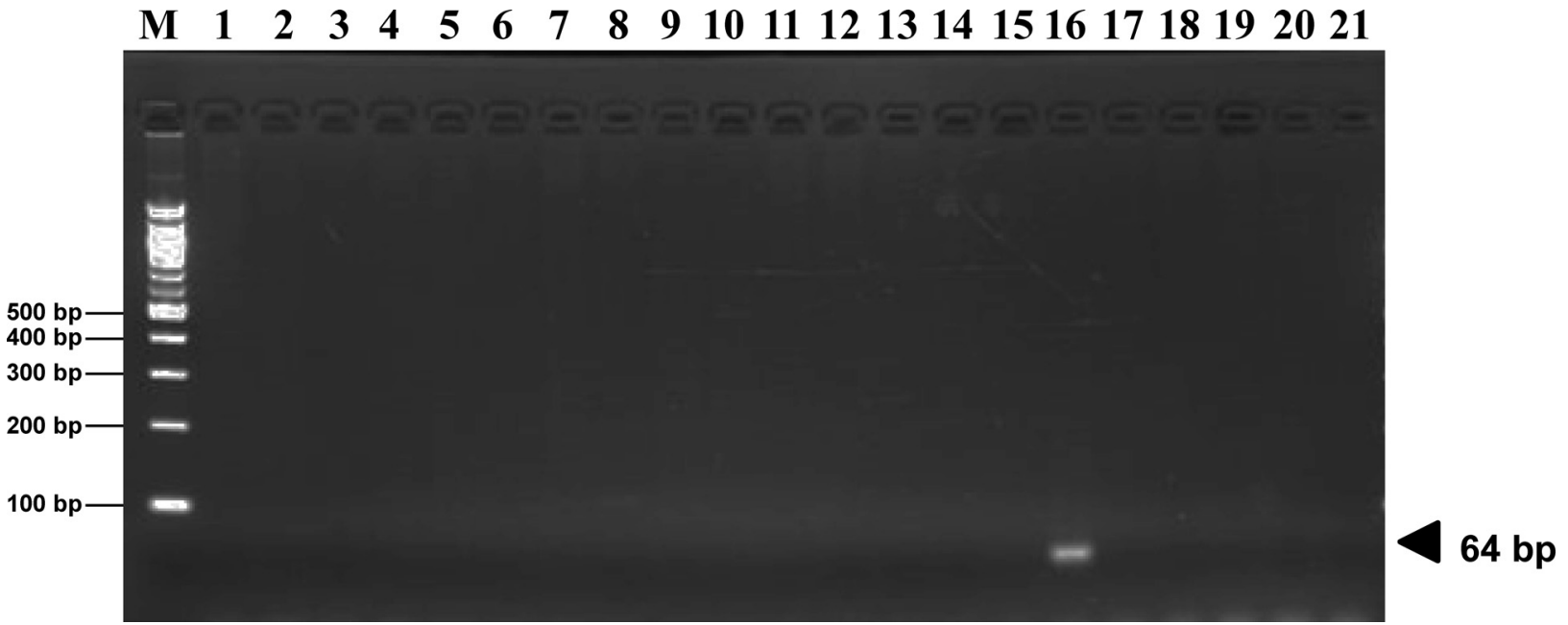

Fig. 2. Specificity test of the designed primer pair for genomic DNAs from several GM events or crops Agarose gel (3.0\%) electrophoretogram of the amplified PCR products corresponding to the $64 \mathrm{bp}$ of A2704-12 DNA. Arrowhead indicates the expected amplified product. Lanes 1-11, eleven GM maize events, namely NK603, Event176, T25, GA21, MON810, TC1507, Bt11, MIR604, MON88017, DAS59122, and MON863, respectively; 12 and 13, non-GM maize and non-GM soy, respectively; 14-17, four GM soybean events, namely, RRS, MON89788, A2704-12, and A5547-127, respectively; 18-21, rice, wheat, barley, and no template, respectively. Lane M shows 100 bp ladder size markers.
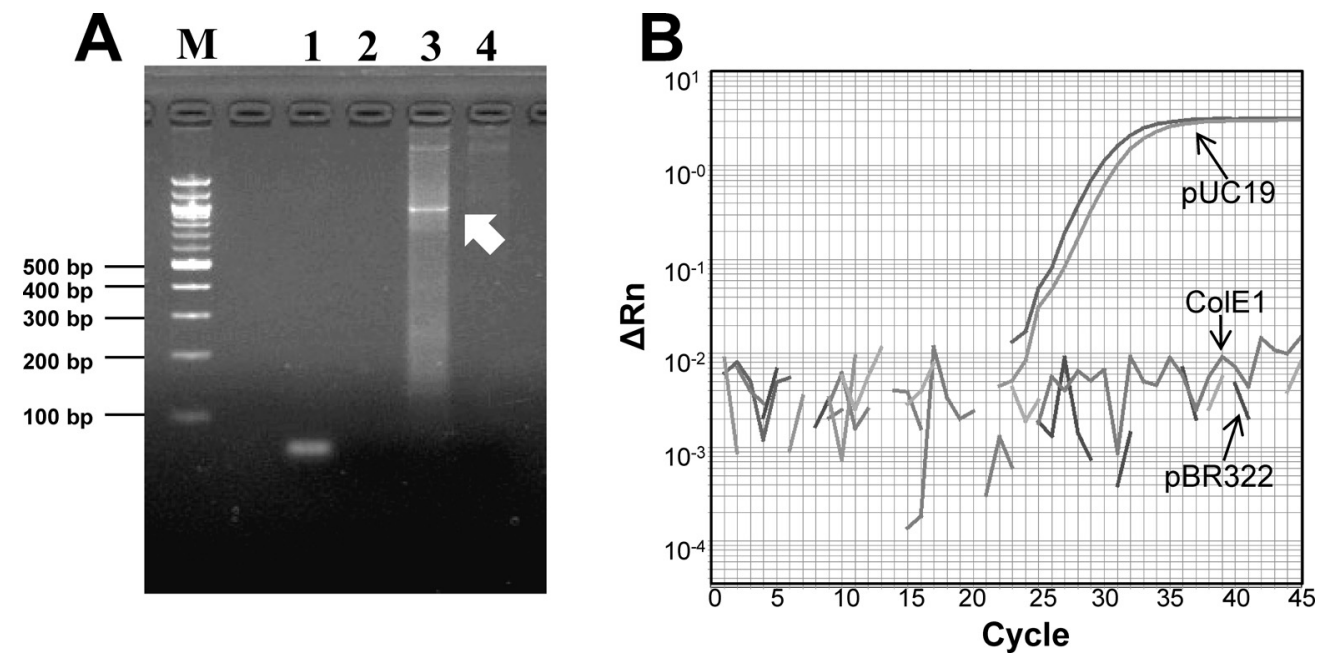

Fig. 3. Specificity test of the designed primer pair and probe for plasmid DNAs

A: Qualitative PCR analysis. Lanes 1-4, A2704-12 genomic DNA, ColE1 DNA, pUC19, and pBR322, respectively. The arrow indicates a non-specific amplification product. Lane M shows $100 \mathrm{bp}$ ladder size markers.

B: Quantitative PCR analysis. pUC19-, pBR322-, or ColE1-derived signals in the amplification profile using the AB 7900 are shown. Concentrations of DNA solutions of A2704-12 genomic DNA, ColE1 DNA, pUC19, and pBR322 were $20,5,10$, and $10 \mathrm{ng} / \mu \mathrm{L}$, respectively.

\section{Construction of calibrant plasmid for A2704-12}

In Japan, one of the features of standard quantitative methods is the utilization of standard plasmid DNA as reference molecules and calibrators. We have developed several standard plasmids ${ }^{8), 17)}$ using pUC19 or pBR322. Although pUC19 is a useful plasmid containing a high-copy-number replicon ${ }^{18)}$, when the pUC19 plasmid was used as a template, a non-specific amplified product of around $1.0 \mathrm{~kb}$ was observed (Fig. 3A). Furthermore, a non-specific signal was detected by quantitative PCR analysis (Fig. 3B). As mentioned above, for the specific detection of A2704-12, the pUC19-derived sequences, KVM175 and SMO001, which are a part of the sequences of bla gene and lac operon, respectively, were used as primers. The unexpected band may have been caused by the sequences of these primers, indicating the possibility that inaccurate quantification could occur if pUC19-based plasmids were used as a calibrator for quantification. Thus, we used pBR322 plasmid for the construction of the standard plasmid, designated as pLLS. To prepare the pLLS plasmid, we removed a bla gene partial sequence that included KVM175 from pBR 322 and then inserted the A2704-12 and Le1 segments (Fig. 4). Figure 5 shows the amplification plots of the pLLS plasmids diluted to a concentration ranging from 20 to 250,000 copies per reaction (Fig. 5A and B). The $R$ 
${ }^{2}$ values from both A2704-12 and Le1 were above 0.999 (Figs. 5C and D), which is an acceptable level $\left(R^{2}\right.$ should be above 0.990$)^{8}$. The slopes, representing the amplification efficiencies, were -3.44 and -3.32 for A2704-12 and Le1 standard curves, respectively. PCR efficiency

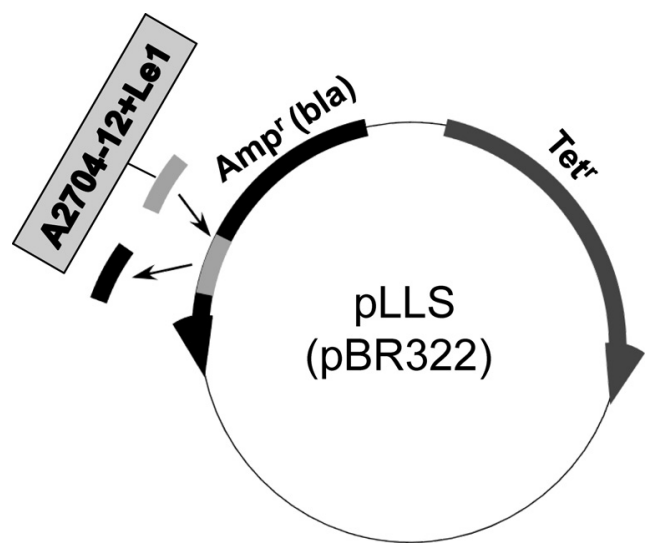

Fig. 4. Schematic diagram of the construction of pLLS plasmid

The region corresponding to positions 36133843 in pBR322 was removed, and the specific sequences of A2704-12 and the Le1 were inserted in tandem. The nucleotide sequence of pBR322 is available under accession number J01749.
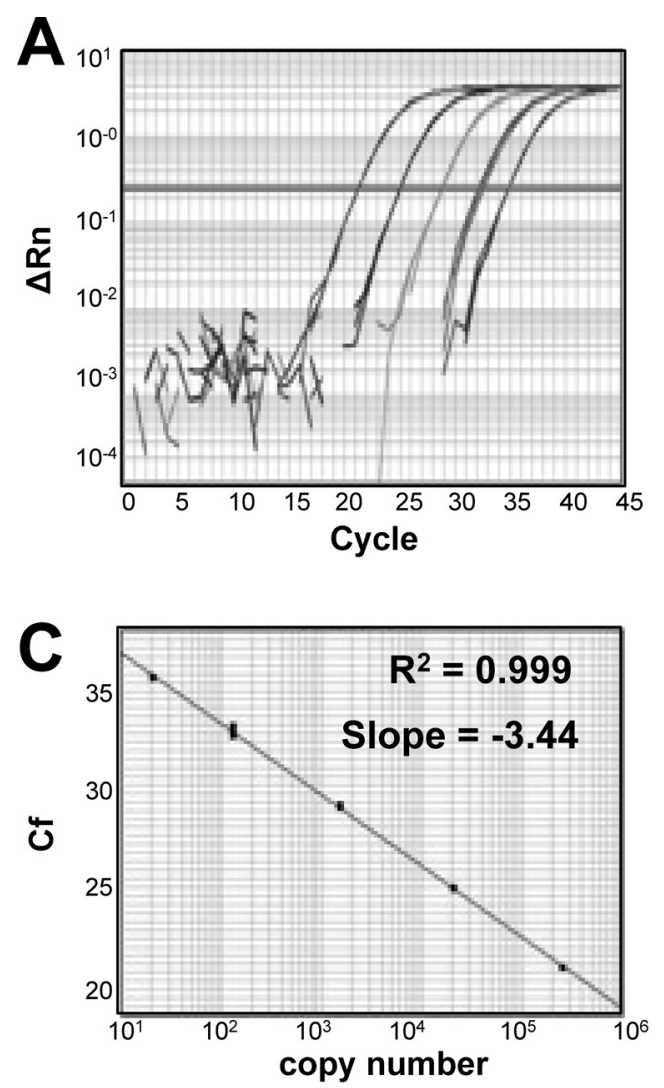

was calculated by use of the following equation: PCR efficiency $=10^{(-1 / \text { slope }) 19)}$. The theoretical value with an efficiency of $100 \%$ in each cycle is 2.00 , and, in this study, PCR efficiencies of 1.95 and 1.99 were obtained for A2704-12 and Le1, respectively.

\section{Determination of the $C_{\mathrm{f}}$ value for A2704-12}

To determine the experimental $C_{\mathrm{f}}$ value for A2704-12, we measured the copy numbers of Le1 and A2704-12 in the extracted DNA from A2704-12 seeds. The $C_{\mathrm{f}}$ value was determined with two real-time PCR instruments (the AB 7900 and the AB 7500) independently, from the results of 5 laboratories for the $\mathrm{AB} 7900$ and 3 laboratories for the AB 7500. The measurement was repeated twice, and the $C_{\mathrm{f}}$ value was determined as the mean of values measured by these laboratories. The determined $C_{\mathrm{f}}$ values with the $\mathrm{AB} 7900$ and the $\mathrm{AB}$ 7500 were similar; in fact, they took the same value of

Table 1. Experimental conversion factor for A2704-12

\begin{tabular}{ccccccc}
\hline \hline & 7900 & & & \multicolumn{3}{c}{7500} \\
\cline { 1 - 3 } \cline { 5 - 7 } Mean & SD & RSD & & Mean & SD & RSD \\
\hline 0.98 & 0.0423 & 4.31 & & 0.98 & 0.0232 & 2.36 \\
\hline
\end{tabular}

SD: Standard deviation

RSD: Relative standard deviation
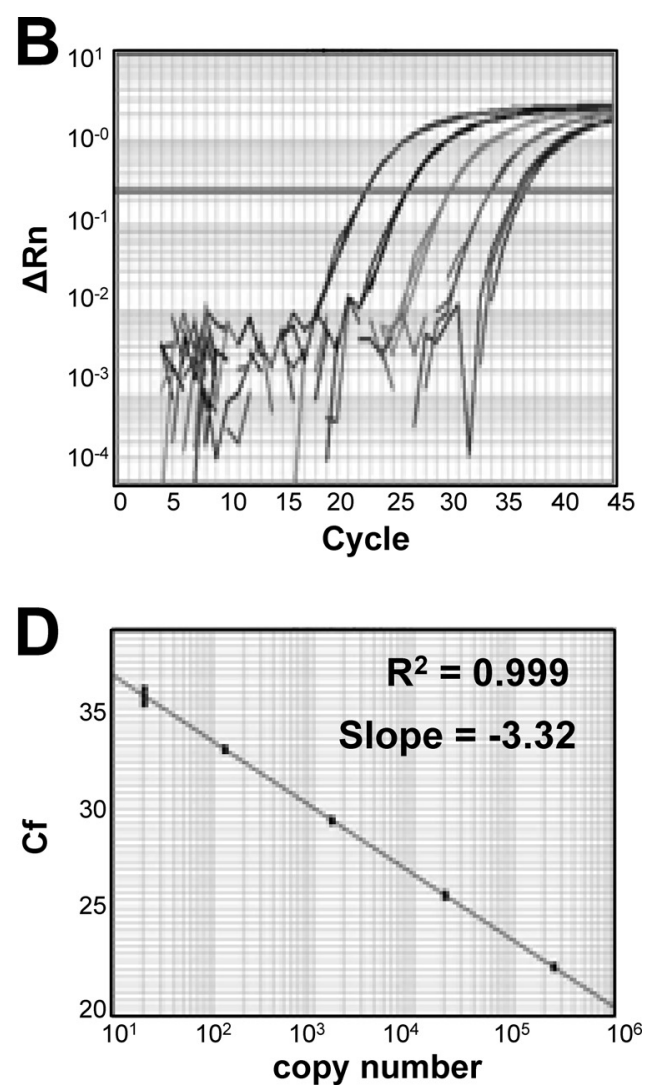

Fig. 5. Amplification plots for dilution series of pLLS plasmid and corresponding curves

Typical amplifications of A2704-12 and Le1 segment are shown in A and B, respectively. The respective standard curves are shown in the panel below, and the $R^{2}$ and slope values of each standard curve are indicated at the upper-right corners. The dilutions contained 250,000, 20,000, 1,500, 125, and 20 initial template copies per reaction, respectively. These analyses were performed with the AB 7900. 
Table 2. Summary of accuracy and precision statistics for real-time PCR by ABI PRISM 7900HT and 7500

\begin{tabular}{|c|c|c|c|c|c|c|}
\hline \multirow{4}{*}{$\begin{array}{l}7900 \mathrm{HT} \\
\%(\mathrm{w} / \mathrm{w})\end{array}$} & \multirow{4}{*}{ Retained labs } & \multicolumn{2}{|c|}{ Trueness } & \multirow{2}{*}{\multicolumn{2}{|c|}{ Precision }} & \multirow{4}{*}{$\begin{array}{l}\text { Detection limit } \\
\text { Below } 20 \text { cipies }^{c}\end{array}$} \\
\hline & & \multirow{2}{*}{ Means } & \multirow{2}{*}{ Bias } & & & \\
\hline & & & & $\operatorname{RSD}_{\mathrm{r}}^{\mathrm{a}}, \%$ & $\mathrm{RSD}_{\mathrm{R}}^{\mathrm{b}}, \%$ & \\
\hline & & GMO Amount, \% & True value, \% & & & \\
\hline 0.10 & 5 & 0.101 & 1.0 & 9.4 & 9.9 & $0 / 10$ \\
\hline 0.50 & 5 & 0.455 & -9.0 & 6.4 & 7.5 & $0 / 10$ \\
\hline 1.0 & 5 & 0.919 & -8.1 & $7.7^{\mathrm{d}}$ & $7.7^{\mathrm{d}}$ & $0 / 10$ \\
\hline 5.0 & 5 & 4.27 & -14.6 & $9.9^{\mathrm{d}}$ & $9.9^{d}$ & $0 / 10$ \\
\hline 10.0 & 5 & 8.96 & -10.5 & 10.7 & 10.7 & $0 / 10$ \\
\hline \multirow{3}{*}{7500} & \multirow{4}{*}{ Retained labs } & \multicolumn{2}{|c|}{ Trueness } & \multirow{2}{*}{\multicolumn{2}{|c|}{ Precision }} & \multirow{2}{*}{ Detection limit } \\
\hline & & Means & Bias & & & \\
\hline & & & Dids & \multirow{2}{*}{$\mathrm{RSD}_{\mathrm{r}}^{\mathrm{a}}, \%$} & \multirow{2}{*}{$\mathrm{RSD}_{\mathrm{R}}{ }^{\mathrm{b}}, \%$} & \multirow{2}{*}{ Below 20 cipies $^{c}$} \\
\hline$\%(\mathrm{w} / \mathrm{w})$ & & GMO Amount, \% & True value, $\%$ & & & \\
\hline 0.10 & 3 & 0.112 & 11.7 & 11.0 & 12.1 & $0 / 6$ \\
\hline 0.50 & 3 & 0.503 & 0.7 & $13.2^{\mathrm{d}}$ & $13.2^{\mathrm{d}}$ & $0 / 6$ \\
\hline 1.0 & 3 & 0.992 & -0.8 & 3.0 & 6.7 & $0 / 6$ \\
\hline 5.0 & 3 & 4.71 & -5.8 & $8.2^{\mathrm{d}}$ & $8.2^{\mathrm{d}}$ & $0 / 6$ \\
\hline 10.0 & 3 & 9.30 & -7.1 & 3.3 & 4.0 & $0 / 6$ \\
\hline
\end{tabular}

a $\mathrm{RSD}_{\mathrm{r}}$ : Repeatability relative standard deviation

${ }^{\mathrm{b}} \mathrm{RSD}_{\mathrm{R}}$ : Reproducibility relative standard deviation

${ }^{\mathrm{c}}$ Number of values less than 20 copies per the total number of retained data.

${ }^{d}$ When $\mathrm{RSD}_{\mathrm{r}}$ was above $\mathrm{RSD}_{\mathrm{R}}, \mathrm{RSD}_{\mathrm{R}}$ was considered to be the same as $\mathrm{RSD}_{\mathrm{r}}{ }^{24)}$.

0.98 rounded to the nearest hundredth of a unit (Table 1). From these results, we used 0.98 in the following quantifications as the common $C_{\mathrm{f}}$ value for the two instruments.

\section{Evaluation of the PCR quantification by multi-laboratory trials}

We performed multi-laboratory trials to evaluate the developed quantitative method for A2704-12 as a blind test using the AB 7900 and the AB 7500 instruments in 5 and 3 laboratories, respectively. We used DNA solution-based blind samples as described previous$1 \mathrm{y}^{20)}$,21). For PCR quantification, analytical procedures would be divided into two main steps, that is, DNA extraction from samples and real-time PCR measurements. In our previous study, the Japanese standard analytical methods ${ }^{* 9}$ which were developed to quantify RRS and several GM maize events, were validated with an interlaboratory study which consisted of 2 steps, namely, DNA extraction and PCR quantification ${ }^{22)}$. After that, the established methods were evaluated with another interlaboratory study which was performed using the same materials without the DNA extraction step ${ }^{23)}$. However, the obtained precisions from the two studies were almost the same, suggesting that, at least in our system, the repeatability of relative standard deviation $\left(\mathrm{RSD}_{\mathrm{r}}\right)$, and reproducibility of relative standard deviation $\left(\mathrm{RSD}_{\mathrm{R}}\right)$ of the DNA extraction step were significantly smaller than those of the PCR quantification step. It was also suggested that the relatively large $R S D_{r}$ and $R S D_{R}$ values which were obtained from GMO quantification, may be attributed to the principle of real-time PCR, which is based on relative quantification between target and taxon-specific sequences, rather than absolute quantification ${ }^{23)}$.

All the participants received primers, probes, and test samples consisting of six different concentrations of A 2704-12, and the measurement was performed twice. All the submitted data were examined for outlier laboratories with extreme variation using Cochran's test $(p<0.025)$ and with an extreme average level using Grubbs' test $(p<0.025)$ for the AB 7900 and the 7500 independently, as previously described ${ }^{22)}{ }^{23)}$, and no outlier was found. The blank sample, 0\% A2704-12, was used to estimate invalid laboratories, and no laboratory was eliminated. We then used all of the submitted data obtained from mixed samples with five different GM contents $(0.1 \%, 0.5 \%, 1.0 \%, 5.0 \%$, and $10.0 \%$ concentrations) for further statistical analyses. The trueness and precision were determined for the $\mathrm{AB} 7900$ and the 7500 as previously described ${ }^{22)}{ }^{23)}$. The mean, bias (mean-value, \%), $\mathrm{RSD}_{\mathrm{r}}$, and $\mathrm{RSD}_{\mathrm{R}}$ of blind samples were measured (Table 2). The determined bias, $\mathrm{RSD}_{\mathrm{r}}$, and $\mathrm{RSD}_{\mathrm{R}}$ for the $\mathrm{AB} 7900$ ranged from $-14.6 \%$ to $1.0 \%$, from $6.4 \%$ to $9.9 \%$, and from $7.5 \%$ to $10.7 \%$, respective1y. The determined bias, $\mathrm{RSD}_{\mathrm{r}}$, and $\mathrm{RSD}_{\mathrm{R}}$ for the $\mathrm{AB}$ 7500 ranged from $-7.1 \%$ to $11.7 \%$, from $3.0 \%$ to $13.2 \%$, and from $4.0 \%$ to $13.2 \%$, respectively. The obtained bias, $\mathrm{RSD}_{\mathrm{r}}$, and $\mathrm{RSD}_{\mathrm{R}}$ here were similar to or within a narrower range than those in previously reported GMO events ${ }^{22), 23)}$. The data below 20 copies were extrapolated from the standard curve in our method because there was no calibrant below 20 copies. In Table 2, all the measured copy numbers of $0.10 \%$ samples were over 20 copies. Therefore, we estimate that the limit of quantitation (LOQ) for A2704-12 is $0.10 \%$ in this method.

We developed a specific quantification method for 
GM soybean A2704-12. The experimentally determined $C_{\mathrm{f}}$ value was 0.98 . The LOQ, trueness, and precision of this method were similar to or better than those of previous methods ${ }^{20)-23)}$. ISO 24276 specifies the LOQ in GMO analysis, and the values are generally observed to have a $\mathrm{RSD}_{\mathrm{R}}$ of $25 \%$ or less at the lowest level ${ }^{* 11}$, all the $\mathrm{RSD}_{\mathrm{R}}$ obtained in this study met this criterion. Therefore, we concluded that the developed method would be applicable for the detection and quantification of A2704-12 to monitor the validity of the food labeling system in Japan.

\section{Acknowledgements}

We would like to thank the following collaborators for their participation in these studies:

FASMAC Co., Ltd., Kanagawa, Japan

Food and Agricultural Materials Inspection Center, Saitama, Japan

Hatano Research Institute, Food and Drug Safety Center, Kanagawa, Japan

Hiroshima Prefectural Technology Research Institute, Public Health and Environment Center, Hiroshima, Japan

Japan Food Research Laboratories, Tokyo

Kanagawa Prefectural Institute of Public Health

National Food Research Institute, Ibaraki, Japan

Tokyo Metropolitan Institute of Public Health

This work was supported by the Ministry of Agriculture, Forestry, and Fisheries of Japan Research Project, "Assurance of Safe Use of Genetically Modified Organisms", and by a grant from the Ministry of Health, Labour and Welfare of Japan and by a grant from Consumer Affairs Agency, Government of Japan.

\section{References}

1) James, C. Executive summary of global status of commercialized biotech/GM crops: 2009. ISAAA Brief 2009, 41 (2009).

2) Hino, A. Safety assessment and public concerns for genetically modified food products: The Japanese experience. Toxicol. Pathol., 30, 126-128 (2002).

3) Thompson, C. J., Movva, N. R., Tizard, R., Crameri, R., Davies, J. E., Lauwereys. M., Botterman, J. Characterization of the herbicide-resistance gene bar from Streptomyces hygroscopicus. EMBO J., 6, 2519-2523 (1987).

4) Wohlleben, W., Arnold, W., Broer, I., Hillemann, D., Strauch, E., Pühler, A. Nucleotide sequence of the phosphinothricin N-acetyltransferase gene from Streptomyces viridochromogenes Tü494 and its expression in Nicotiana tabacum. Gene, 15, 25-37 (1988).

5) De Beuckeleer, M. Elite event A2704-12 and methods and kits for identifying such event in biological samples. Patent No. WO 2006/108674 A2, 2006.

6) De Beuckeleer, M. Elite event A5547-127 and methods and kits for identifying such event in biological samples.

*11 International Standard 24276, Foodstuffs-Nucleic acid based of analysis for the detection of genetically modified organisms and derived products-General requirements and definitions.
Patent No. WO 2006/108675 A2, 2006.

7) Berdal, K. G., Hols-Jensen, A. Roundup Ready soybean event specific real-time quantitative PCR assay and estimation of the practical detection and quantification limits in GMO analyses. Eur. Food Res. Technol., 213, 432-438 (2001).

8) Kuribara, H., Shindo, Y., Matsuoka, T., Takubo, K., Futo, S., Aoki, N., Hirao, T., Akiyama, H., Goda, Y., Toyoda, M., Hino, A. Novel reference molecules for quantification of genetically modified maize and soybean. J. AOAC Int., 85, 1077-1089 (2002).

9) Huang, C. C., Pan T. M. Event-specific real-time detection and quantification of genetically modified Roundup Ready soybean. J. Agric. Food Chem., 53, 3833-3839 (2005).

10) Zhang, H., Yang, L., Guo, J., Li, X., Jiang, L., Zhang, D. Development of one novel multiple-target plasmid for duplex quantitative PCR analysis of Roundup Ready soybean. J. Agric. Food Chem., 56, 5514-5520 (2008).

11) Liu, J., Guo, J., Zhang, H., Li, N., Yang, L., Zhang, D. Development and in-house validation of the eventspecific polymerase chain reaction detection methods for genetically modified soybean MON89788 based on the cloned integration flanking sequence. J. Agric. Food Chem., 57, 10524-10530 (2009).

12) Vodkin L. O., Rhodes P. R., Goldberg, R. B. cA lectin gene insertion has the structural features of a transposable element. Cell, 34, 1023-1031 (1983).

13) Akiyama, H., Sakata, K., Spiegelhalter, F., Furui, S., Nakashima, A., Kitta, K., Teshima, R. Interlaboratory validation of an event-specific real time polymerase chain reaction detection method for genetically modified DAS 59132, maize. Shokuhin Eiseigaku Zasshi (Food Hyg. Saf. Sci. Japan), 51, 65-70 (2010).

14) Cochran, W. G. The distribution of the largest of a set of estimated variances as a fraction of their total, Annals of Eugenics, 11, 47-52 (1941).

15) Grubbs, F. E. Samples criteria for testing outlying observations. Ann. Math. Statist. Assn., 21, 27-58 (1950).

16) Grubbs, F. E. Procedures for detecting outlying observations in samples, Technometrics, 11, 1-21 (1969).

17) Oguchi, T., Onishi, M., Chikagawa, Y., Minegishi, Y., Kodama, T., Akiyama, H., Ohno, Y., Futo, S., Hino, A., Furui, S., Kitta, K. Development of event-specific quantitation method for GA21 maize, which is a GM event without CaMV35S promoter. Shokuhin Eiseigaku Zasshi (J. Food Hyg. Soc. Japan.), 49, 16-22 (2008).

18) Bartolomé, B., Jubete, Y., Martínez, E., de la Cruz, F. Construction and properties of a family of pACYC184derived cloning vectors compatible with pBR322 and its derivatives. Gene, 102, 75-78 (1991).

19) Rott, M. E., Lawrence, T. S., Wall, E. M., Green, M. J. Detection and quantification of Roundup Ready soy in foods by conventional and real-time polymerase chain reaction. J. Agric. Food Chem., 52, 5223-5232 (2004).

20) Takabatake, R., Futo, S., Minegishi, Y., Watai, M., Sawada, C., Nakamura, K., Akiyama, H., Teshima, R., Furui, S., Hino, A., Kitta, K. Evaluation of quantitative PCR methods for genetically modified maize (MON863, NK603, TC1507 and T25). Food Science and Technology Research, 16, 421-430 (2010).

21) Takabatake, R., Onishi, M., Koiwa, T., Futo, S., Minegishi, Y., Akiyama, H., Teshima, R., Furui, S., Kitta, K. Establishment and evaluation of event-specific quantitative PCR method for genetically modified soybean MON 89788. Shokuhin Eiseigaku Zasshi (Food Hyg. Saf. Sci.), 
51, 242-246 (2010).

22) Shindo, Y., Kuribara, H., Matsuoka, T., Futo, S., Sawada, C., Shono, J., Akiyama, H, Goda, Y., Toyoda, M., Hino, A. Validation of real-time PCR analyses for line-specific quantitation of genetically modified maize and soybean using new reference molecules. J. AOAC Int., 85, 11191126 (2002).

23) Kodama, T., Kuribara, H., Minegishi, Y., Futo, S., Watai,
M., Sawada, C., Watanabe, T., Akiyama, H., Maitani, T., Teshima, R., Furui, S., Hino, A., Kitta, K. Evaluation of modified PCR quantitation of genetically modified maize and soybean using reference molecules: Interlaboratory study. J. AOAC Int., 92, 223-233 (2009).

24) Horwitz, W. Protocol for the design, conduct and interpretation of method-performance studies. Pure \& Appl. Chem., 67, 331-343 (1995). 